\title{
Research on the Impact of Institutions on the Government and the Public in the Context of the Covid-19
}

\begin{abstract}
Qifan Zhang
${ }^{1}$ Luhe international Academy, Tongzhou, Beijing, China. 101110

*Corresponding author. Email Address: 2736396979@qq.com

ABSTRACT

During Covid-19, Government has heterogeneity in fighting the pandemic and the general public also share a different level of suffering. The main contributor of these issues is supposed to be pointed at institutional factors. Nations with inclusive institutions, advocating for equality in human rights and innovations, protected themselves timely, and it's positive learning environment do facilitate the process of vaccine development. In sharp contrast, nations with extracted institutions are exceedingly vulnerable in this pandemic since the disease provides a great chance for the privileged people to exploit the underprivileged people and are unable to escape from this pandemic in a short term. Hence, the winners and losers were set long before the pandemic is coming.
\end{abstract}

Keywords: Extracted institution, Inclusive institution, Government behaviors, Covid-19, The public

\section{INTRODUCTION}

Covid-19,or called coronavirus, is a high-contagious disease that has arrived and settled on the Earth for almost two years. After being named by the WHO (World Health Organization) in January 2020,the disease started to be the main topic discussed by both the general public and the government. Gradually, there happened to be a significant difference in the government responses from each nation even though China, as a pioneer in this virus-fighting game, already showed the necessary procedures. Institutional factors cited by the book "Why Nations Fail: The Origin of Power, Prosperity and Poverty" [1] does account for this heterogeneity of government responses and the different levels of suffering the general public share in countries that have separate institution. Hence, this article would be mainly focused on how do these institutions affect government behaviors and public lives during the pandemic. Plus, this article would further analyze the reason that some nations are suffered under constant high employment rates, how does overpricing takes over the market in South Africa, and high social contributions in nations, such as the United States and China. The methodology used in this article is analyzing the Economic situations and progress in fighting the pandemic of nations with separate institutions, then forming a conclusion based on international data. Only by understanding the role of institutions playing in Covid-19,people could understand how much inequality both in Wealth and Rights is distributed in the world.

\section{INSTITUTIONAL EFFECTS ON GOVERNMENT BEHAVIORS DURING COVID-19}

\subsection{Extracted and Inclusive Institutions}

Initially, there are hundreds of nations on the Earth, and they could be generalized into two separate groups based on their institution difference. The extracted institution, as mentioned in the book "Why Nations Fail: The Origins of Power, Prosperity, and Poverty", is the only determining factor that causes the inequality of the world, creating the poorness of nations. Specifically, this textbook illustrates extracted institution as an institution that extracts income and wealth from one subset of society to a different subset. That is to say, a smaller proportion of the population, the elite group, gets to decide who is going to gain more capital and who is going to get less. One famous example is from North Korea. According to the article "Political, Social and Economic Inequality in North Korea" [2], the 
specific institution North Korea uses is called the Songbun System. The Songbun System characterizes its people on the spectrum of trustworthiness, and the system divides its citizens into three classes: the core, wavering, and hostile classes. Based on 2006 Song report, the according to the proportion of people in these three classes is: 28 percent, 45 percent, 27 percent, and it's heretically placed in order. Additionally, the extracted institutions discouraged people from innovating and self-improving because of their high burden of living pressure. According to the 1998 UN childhood malnutrition data, only 32 percent of the children revealed no malnutrition, while the main part of the teenagers has somewhat suffered from malnutrition.

Furthermore, the other type of institution is called an inclusive institution, settled in the richest nations in the world, such as South Korea, United States, and England. In sharp contrast to the Extracted Institution which plays a monopoly role in both political and economic environments, the inclusive institution stands for democracy. The central government spread its power to the state governments and to a plethora of representatives governed by people, eliminating all the priorities one might have when they were born and giving the people every right to attain a better prospect even though ones came from nothing. Besides, the inclusive institution could encourage people to deliver more innovations and new businesses to the country. Take the United States, the biggest economic system in the world, for example. There was a newspaper that illustrated that the majority of Americans would choose to start a new business if they had the chance.

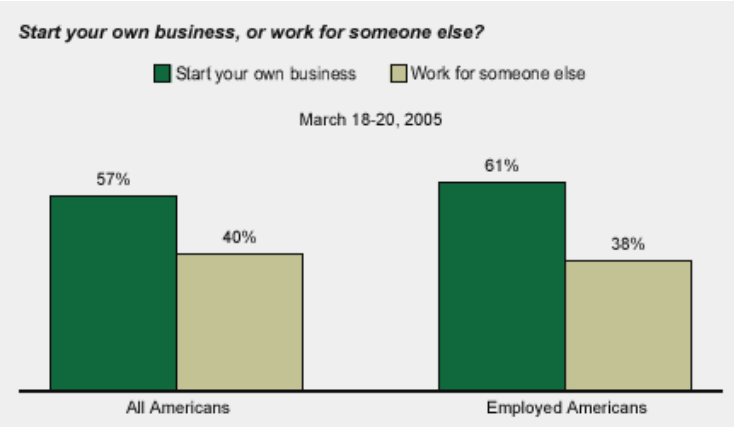

Figure1: Americans' ambitions on starting a new business

Based on this graph, Employed Americans typically contain a more ambitious dream than unemployed ones partially because the working culture in America shapes people into innovative beings and the stable Economy in the United States also reduced the fear of starting new business. Unlike in North Korea, Americans could start a business right away without being afraid of high tax burdens and plenty of restrictions given by the government.

\section{2. the Influence of Extracted Institution on Fighting Covid-19}

As the explanation of extracted institution is given, how monopoly and inequality powers affect the strategies of government become exceedingly significant.

On the one hand, the ignorance of the pandemic is really common at the beginning period by some countries, such as Kenya, and other sub-Saharan nations.

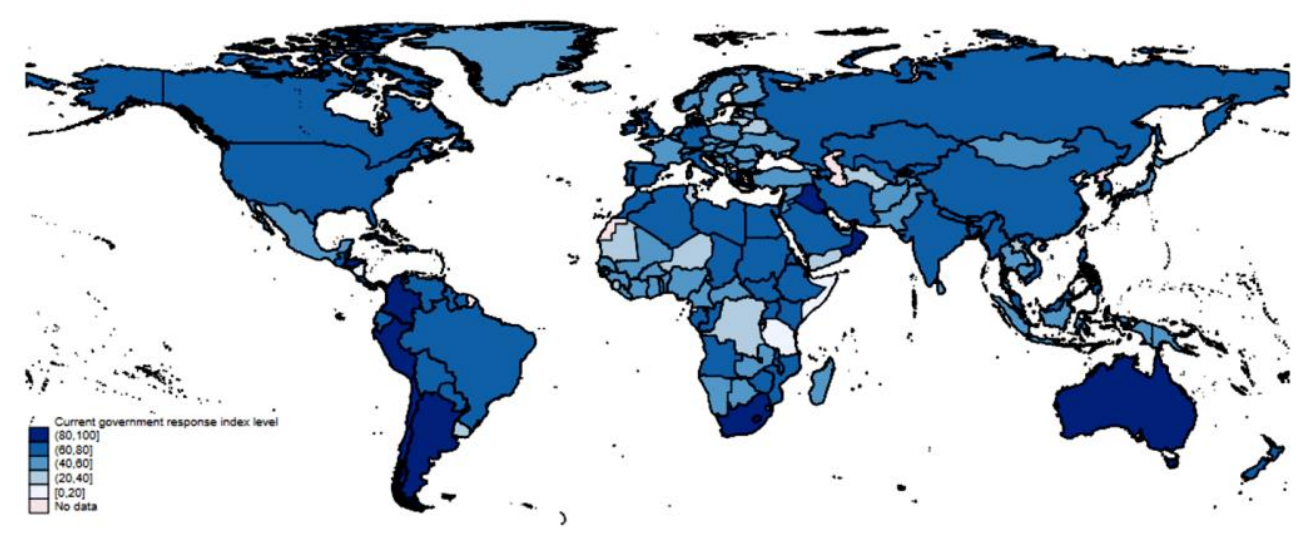

Figure2: Government response world-wide

This graph illustrates that sub-Saharan countries, the poorest countries, have some of the lowest government response indexes in the world, while other nations, such as United States,Australia, and China, are very quick-minded, containing some of the highest government index number in the world. That is because, those nations with low government response index have an intrinsically corrupted political system that delayed 
the whole fighting process. One property discussed in the definition of the extracted institution is its inequality in power or status. The dictators, sometimes covered under the title of Democracy, contain every right to decide who is going to gain more of the life-saving products, such as a ventilator, vaccines, and masks, and who is going to gain less. Take Kenya as one example. Kenya has been long ruled by the family Kenyatta, and it is certainly now one of the worst cases of fighting Covid-19. According to the article "The Political-Economy of Covid-19 and Security in Western Kenya"[3], a large amount of population who have been staying unemployed or in economic inactivity, lacking of the income stream, have an increasing involvement in violation, crime, and conflict. Plus, the government only did a partial job to lock down few cities, and the asymptomatic transmissions are spreading frequently, leaving a total mysterious ending to the disease-fighting of Kenya. However, partially because of the incapability of administering the pandemic on a large scale, the main reason for the imperfection of government policies is that the government is not governed by people. Governments with excessive priorities and powers would have the least incentives to lock down the cities at the expense of the whole Economy since the power and class distribution is tilted.

On the other hand, the essence of lack-of-innovation in extracted institutions would finally lead to the incapability of developing own vaccines. Today's vaccine manufacturers are all the nations with inclusive institutions, such as China, England, and United States. The main contributors to this monopoly status of vaccines in the richest countries in the world are really obvious and highly related to the positive environment in medical industry. The pharmacists and doctors have a high social status in those countries and all they need to do is developing the vaccine with the most advanced equipment, most professional members from leading universities, and the most plentiful resources providing thousands of times more of error-tolerant rate than those countries which could only depend on imported raw materials and have to fight with the embargos from other countries. Thus, the nations with extracted institutions have to pay for the expensive and limited vaccines from the manufacturer's thousands of kilometers away, which further burdens the taxes on the public.

\section{3. the Influence of Inclusive Institution on Fighting Covid-19}

There are two overall benefits that inclusive institutions would provide in fighting the pandemic.

Firstly, governments with inclusive institutions would always prioritize the public's interest. Especially during the Covid-19, most countries in the world are suffering under the threat of ever-increasing inequalities in Health Care caused by the favoritism to the interest class, while the leading countries are spreading their vaccines and leaving the medicines accessible at an affordable price for most people. Take the United States for example. The number of people taking the full round vaccine has reached 51.7 percent of the whole population in the US till 15th August due to the lobbies and advertisements of the significance of vaccination delivered by the government. Plus, the United States almost has settled the vaccination spot in every main city, reducing the transportation cost and time cost for individual; In the deeper analysis of this strategy, the United States further reduced the inequality in Health Care within their country. In sharp contrast, Egypt, as one of the representatives of nations with extracted institutions, has only approximately 2.1 percent of the whole population taken the vaccines. Granted, there are people in both Egypt and United States who had a previous belief that vaccines are harmful to the body. However, a larger proportion of the people who did not take the vaccines are not due to their own beliefs, but rather, either they don't have enough vaccines or the limited vaccines are controlled by the privileged group.

Secondly, inclusive institutions served as the economic propellers to cover the original loss from the pandemic. Particularly, the pandemic is not only a tragedy for the poor countries, but also the rich ones. Again, take the United States as an example.

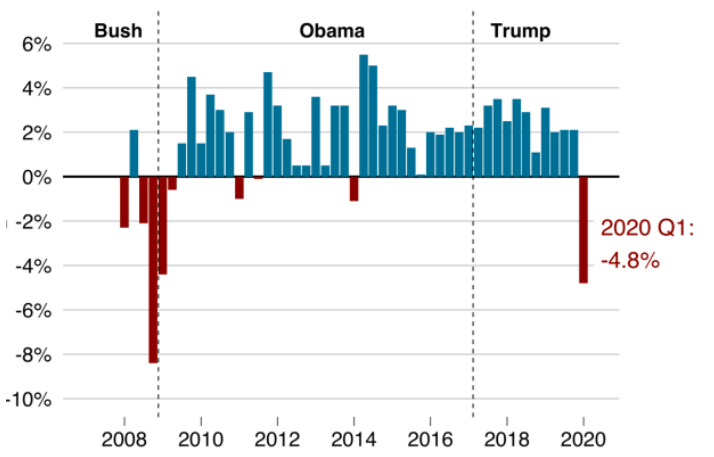

Figure3:The change in Economic growth in the United States

This graph shows the accurate deficit of the United States' economic growth in the term of Donald Trump's presidency, and it almost reaches the loss twelfth Financial Crisis brought the United States in 2008. In the starting period of the pandemic, the amount of money spent on Public Health and the economic stagnation caused by school and working place closure cost an astronomical figure for both the private and public companies. After one year of economic inactivity from 2020 to 2021 throughout the country, the recovering policies are set in different states to encourage people to get back to work, eliminating the negative effects on economics generated by the Covid-19. According to recent reports online, the United States do have a bouncing-up sign in their 
economic growth, and it proves that their policies contain high efficacy and low time lags. One main contributor to its high efficacy is that the United States has a political system providing equal chances and easy access to the new comers of the market with little restrictions. Even though the competition is going to be extremely intense for the market, people are still willing to contribute to the aggregate economy and be self-improving in their careers. Nevertheless, countries, such as Peru, North Korea, and Mexico, would probably take few years to see the backing-up sign in their reports. Their political system does not guarantee people's living subsistence; thus, it generally staggers people to start a business and take the risk of being bankrupted.

\section{INSTITUTIONAL EFFECTS ON THE GENERAL PUBLIC DURING COVID-19}

\subsection{System-induced Unemployment}

To start with, government would selectively ignore many issues from the pandemic due to the conflict of interest of locking down main cities, as mentioned in previous context; therefore, the covid-19 is never going to be ended for the next few years. Unlike rich nations with inclusive institution, countries, such as Kenya, Egypt, and other sub-Saharan regions, are not affordable of millions of medicines and vaccines to cure their patients, and based on the herd immunity theory, there is going to be at least sixty seventy percent of the population being infected in order to achieve the threshold of herd immunity. Thus, the actual number of required infected cases will be a horrific figure. Take Egypt as an example. Egypt has 99375741 people in their realm. That is, the government needs several 66581746 people to be infected in order to successfully pass the pandemic. Due to the average transmission rate of infection, either symptomatic and asymptotic, the daily increase in case number is about two hundred per day. As a result, the only option left for the Egyptian government is simply living with the pandemic in the terror of disease. Similarly, according to the Human Sciences Research Council[6], this survey found out that $54 \%$ of South Africans viewed themselves as moderate to high risk for contracting the virus, suggesting some level of anxiety about their current situation. Hence, fewer and fewer people would be encouraged to start a new business where the majority of the population are in terror of their health issues and worried about their private assets being rubbed due to loose security, and old businesses would be closed since the economic inactivity takes over the country slowly. The unemployment rate for Kenya, the other country with an extracted institution, is approximately 39.1 percent, and Egypt also shares one of the highest unemployment rates it experienced throughout history in 2020 . The countries with an extracted institution have some intrinsic shortcomings that disabled the plan to eliminate the virus in a short term.

\subsection{Skyrocketing Prices for Life-saving necessities}

One of the definitions of extracted institution is that there are a small proportion of the population holding priorities and monopoly powers in the market. During the Coronavirus, things, such as masks and ventilators, are limited in numbers and are the "saviors" of all nations. Nevertheless, the medical equipment is very rare in some Africa countries, and the shortage of life-saving facilities are usually being utilized by the privileged families for sales. Hence, the misuse of market power and the imbalance distribution of human values eventually result in overpricing, especially in an extracted institution where the government control on monopoly powers is merely a paper work. According to the article"Transnational Kleptocracy and the COVID-19 Pandemic Containing the Spread" [5], it clearly states that:"In South Africa, rampant overpricing of personal protective equipment (PPE) and widespread fraud has created a political crisis." That is, government restrictions and supervisions should be implemented and correctly performed during any pandemics; otherwise, the inequality of human rights will be taken advantage of by businessmen, politicians, and other elites. However, nations with an extracted institution would consistently have this issue in any pandemics, wars, or financial crisis. The only way to resolve such issues or at least reduce the cases is to convert into an inclusive institution where human rights and powers are equally distributed. Under inclusive institution, market prices will be strictly supervised and monopolies will be restrained by the anti-trust laws, hence the pricing of personal protective equipment could be within a reasonable range

\subsection{High Dedication Level and Social Conformity}

Citizens under an inclusive institution would have high dedication levels and high social conformity in the pandemic. Specifically, equality in rights, powers, and wealth played a huge role when the pandemic came along. Based on the second proposal of the article "Coordination and Social Distancing: Inertia in the Aggregate Response to COVID-19" [4], it points out that "The aggregate action in each period depends on all average higher order beliefs in the population about the right action". That is, the actual payoff of the aggregate group is highly related to the social conformity and the trust in the government. A powerful, reliable government could increase the efficacy of the disease-fighting policies and involve more people who prefer to be high contributors to the nation. Take the public good game for an instance. More than two 
players are the decision makers, and they would make their decisions simultaneously. They all have private bank accounts and as a group, they have a shared group account. Both of them will be given the same amount of money for experimental use, 10 dollars for example, and they would have their choices on how much they put on the private account and how much to the group account. Here is a payoff function for individuals.

$$
\mathrm{y}_{\mathrm{i}}=\mathrm{E}_{\mathrm{i}}-\mathrm{C}_{\mathrm{i}}+(\mathrm{mpcr}) *\left(\sum \mathrm{C}_{\mathrm{j}}\right)
$$

The Ei represents how much this participant owns originally, and the $\mathrm{Ci}$ means how much this participant devote to the group account. So, the left side of the equation simply means how much the participant owns privately. MPCR(marginal per capita return), on the right side of the equation, means how likely participants would make devotion. Then, multiplying the MPCR value by the sum of all players devotion. Therefore, the right side of the equation represents how much the participant gain from this group.

Hypothetically, the game is playing in a Covid-19 background, and the group accounts refer to the total budges for vaccine development and Public Health Care. For the first round,citizens under an inclusive institution are likely to show higher devotion than citizens governed by privileged people since the equality in rights, power, and wealth create the trust in the government and the risk of being deceived, misused, and betrayed is minimized in a democratic nation. That is, the variable marginal per capital return is usually higher in nations with an inclusive institution. In a repeated public goods game, the information of the group's actions will be shared with the members. Therefore, if all players chose to devote more than fifty percent of their money into group accounts,as mentioned, the rest of the rounds except the last round would have approximately ninety percent of the chance to keep being a high contributor. For the last round, everyone has the incentive to devote less to the group account since they know that corporations are ended and this round's "laziness" won't affect the overall game. However, people under inclusive institutions are gaining more profits at the end of the pandemic theoretically.

\section{CONCLUSION}

To sum up, this article mainly deals with how two different institutions affect both government and the general public during the pandemic. Besides, this article also points out that winners and losers are determined by their institutions and it's set long before the pandemic. However, there are some shortcomings in the perspectives mentioned previously. Initially, there aren't enough data and experiments to support some theories, and most of the theories come from different articles, which might as well be inaccurate. Hence, it may not be an accurate conclusion for some scientists or sociologists. Furthermore, some of the perspectives derive from untested observations and reflections of some articles; thus, they haven't been tested and verified by platforms. Granted, this article may not satisfy the entire audience group; nevertheless, there will be a period for this pandemic, and the time could tell how do China, United States, Kenya, and Egypt's governments react over time. In the future, this article would be much more convincing if the after-behaviors for both the general publican the government are recorded. What we could do now is merely a prediction based on limited data.

\section{ACKNOWLEDGMENT}

I have to thank for my parents who provided some real groundbreaking thousands since they all love reading newspapers, and I have to Thank for Professor Putterman, Brown University, and John Komlos, Phd, who taught me in the Harvard Summer School. They are all my enlighteners and this article won't even be completed if they did not deliver many good lectures to me.

\section{REFERENCES}

[1] Acemoglu D, \& Robbinson J. March 20th, 2012. "Why Nations Fail: The Origin of Power, Prosperity and Poverty". Crown Business.

[2] Patterson, Z. (2017). Political, Social and Economic Inequality in North Korea. $<\mathrm{i}>$ North Korean Review, $</ \mathrm{i}>\quad<\mathrm{i}>13</ \mathrm{i}>(1), \quad 63-84 . \quad$ Retrieved August 18, 2021, from http://www.jstor.org/stable/26396109

[3] Fredrick Ogenga \& Castro Baraza. April, 2020. The Political-Economy of Covid-19 and Security in Western Kenya. Policy Brief, No. 2. http://41.89.203.227/bitstream/handle/123456789/ 2207/The\%20Political-Economy\%20of\%20Covid$19 \% 20$ and $\% 20$ Security $\% 20 \mathrm{in} \% 20 \mathrm{Western} \% 20 \mathrm{Ke}$ nya.pdf? sequence $=1 \&$ is Allowed $=y$

[4] Shadmehr, Mehdi and Bueno de Mesquita, Ethan, Coordination and Social Distancing: Inertia in the Aggregate Response to COVID-19 (April 17, 2020). University of Chicago, Becker Friedman Institute for Economics Working Paper No. 2020-53, Available at SSRN: https://ssrn.com/abstract=3586839 or http:// dx.doi.org/10.2139/ssrn.3586839

[5] Melissa Aten, Transnational Kleptocracy and the COVID-19 Pandemic Containing the Spread, March 2021, Global insights, https://www.ned.org/wp-content/uploads/2021/03/ 
Global-Insights-Transnational-Kleptocracy-COVI

D-19-Pandemic-March-2021.pdf\#page $=10$

[6] Human Sciences Research Council. (2020). HSRC responds to the COVID: 19 outbreak. http://www.hsrc.ac.za/uploads/pageCont ent/11529/COVID-19\%20MASTER\%20SLIDES \%2026\%20APRIL\%202020\%20FOR\%20MEDIA $\%$ 20BRIEFING\%20FINAL.pdf 